Tohoku J. Exp. Med., 2021, 253, 1-2

\title{
Editorial
}

\section{Toward the Next 100 Years of the Tohoku Journal of Experimental Medicine}

\author{
Kazuhiro Takahashi ${ }^{1}$ \\ ${ }^{1}$ Editor-in-Chief, Tohoku Journal of Experimental Medicine, Sendai, Miyagi, Japan
}

Tohoku J. Exp. Med., 2021 January, 253 (1), 1-2.

Prof. Shigeki Shibahara served as the Editor-in-Chief of the Tohoku Journal of Experimental Medicine (TJEM) during 2003 to 2020. A lot of innovations and changes have been done in the TJEM during these 18 years. Particularly, all the articles published in the TJEM became to be open-access for everyone in the world. We appreciate very much the J-STAGE and the Japan Science and Technology Agency (JST) for the co-operation with the TJEM since 2004. The number of the submitted manuscripts increased from 204 in the year 2003 to 622-749 in the recent six years (Table 1). We now receive manuscripts from all over the world, including the Asian, European, African, and North and South American countries. The acceptance ratio of the submitted manuscripts has ranged from $13 \%$ to $17 \%$ in the recent six years. The impact factor of the TJEM elevated from 0.371 in the year 2003 to 1.584 in the year 2018. Cited half-life has been continuously long, and ranged from 7.7 to 9.5 years during recent five years. The 5-year impact factor of the TJEM (1.625 in the year 2018 and 2019) is rather higher than the impact factor. These data indicate that the articles in the TJEM are cited for a long time. We appreciate Prof. Shigeki Shibahara for his sincere dedication to the TJEM for 18 years.

The Great East-Japan Earthquake (magnitude 9.0) attacked the Tohoku region (northeastern Japan) with Tsunami on March 11, 2011 (Shibahara 2011). Disasterprevention science and earthquake/tsunami research has been the important fields of the TJEM since the Great EastJapan Earthquake (Shibahara 2012; Ishigaki et al. 2013). The TJEM is now open to all the branches of medical sciences, including basic medicine, social medicine, clinical medicine, nursing science and disaster-prevention science. The PubMed search by Sasaki et al. (2020) showed that the most abundant topics of articles on public health and hospitals business continuity plans (BCPs) were pandemic and infectious diseases. Indeed, the coronavirus disease 2019 (COVID-19) is the biggest risk and global health crisis we have faced. The TJEM published three review articles on COVID19 in 2020 (Baloch et al. 2020; Delgado et al. 2020; Ornelas-Ricardo and Jaloma-Cruz 2020), and we hope these publications contribute to the overcome of COVID-19.

In January 2021, the Editor-in-Chief of the TJEM is taken over by Kazuhiro Takahashi, the author of this editorial. As introduced in the editorial published in the first

Table 1. Impact factor, 5-year impact factor, cited half-life, total cites, and the number of submissions and publications per year of the Tohoku Journal of Experimental Medicine in 2003 and the recent 6 years.

\begin{tabular}{lrrrrrrr}
\hline Year & 2003 & 2015 & 2016 & 2017 & 2018 & 2019 & 2020 \\
\hline Impact factor* & 0.371 & 1.287 & 1.278 & 1.423 & 1.584 & 1.441 & - \\
5-year impact factor* & & 1.454 & 1.450 & 1.502 & 1.625 & 1.625 & - \\
Cited half-life* & 9.7 & 7.7 & 8.6 & 8.9 & 9.2 & 9.5 & - \\
Total cites* & 733 & 2,802 & 2,798 & 2,906 & 2,905 & 3,140 & 3,212 \\
Number of submissions & 204 & 678 & 749 & 687 & 692 & 622 & 739 \\
Number of publications & 88 & 123 & 120 & 116 & 103 & 100 & 107 \\
\hline
\end{tabular}

- , not available yet.

*Data are from the WEB of Science on January 5, 2021 (Clarivate Analytics, Philadelphia, PA).

Published online January 16, 2021; doi: 10.1620/tjem.253.1.

Correspondence: Kazuhiro Takahashi, M.D., Ph.D., Department of Endocrinology and Applied Medical Science, Tohoku University Graduate School of Medicine, 2-1 Seiryo-machi, Aoba-ku, Sendai, Miyagi 980-8575, Japan.

e-mail: ktaka-md@med.tohoku.ac.jp

(C)2021 Tohoku University Medical Press. This is an open-access article distributed under the terms of the Creative Commons Attribution-NonCommercial-NoDerivatives 4.0 International License (CC-BY-NC-ND 4.0). Anyone may download, reuse, copy, reprint, or distribute the article without modifications or adaptations for non-profit purposes if they cite the original authors and source properly.

https://creativecommons.org/licenses/by-nc-nd/4.0/ 
issue of the year 2020 (Takahashi and Shibahara 2020), TJEM was founded in 1920 by Prof. Toshihiro Fujita, Prof. Toyoziro Kato and Prof. Yasutaro Satake, who were young professors aged 36 to 43 years old in Tohoku Imperial University, Medical School. These three founding editors of the TJEM presumably hoped to internationally publish original articles written by young researchers from Sendai, Japan via the TJEM. We hope to keep the tradition of the TJEM, and continue to publish excellent original articles, particularly by young researchers in medical science. Now, the TJEM is going toward the next 100 years with a century of tradition.

\section{References}

Baloch, S., Baloch, M.A., Zheng, T. \& Pei, X. (2020) The coronavirus disease 2019 (COVID-19) pandemic. Tohoku J. Exp. Med., 250, 271-278.

Delgado, C.A., Shimabuku, R.L. \& Chiroque-Solano, P.M. (2020) COVID-19 waves: importance of accumulative mortality per million inhabitants. Tohoku J. Exp. Med., 251, 47-49.

Ishigaki, A., Higashi, H., Sakamoto, T. \& Shibahara, S. (2013) The Great East-Japan Earthquake and devastating tsunami: an update and lessons from the past Great Earthquakes in Japan since 1923. Tohoku J. Exp. Med., 229, 287-299.

Ornelas-Ricardo, D. \& Jaloma-Cruz, A.R. (2020) Coronavirus disease 2019: hematological anomalies and antithrombotic therapy. Tohoku J. Exp. Med., 251, 327-336.

Sasaki, H., Maruya, H., Abe, Y., Fujita, M., Furukawa, H., Fuda, M., Kamei, T., Yaegashi, N., Tominaga, T. \& Egawa, S. (2020) Scoping review of hospital business continuity plans to validate the improvement after the 2011 Great East Japan Earthquake and tsunami. Tohoku J. Exp. Med., 251, 147-159.

Shibahara, S. (2011) The 2011 Tohoku earthquake and devastating tsunami. Tohoku J. Exp. Med., 223, 305-307.

Shibahara, S. (2012) Revisiting the March 11, 2011 earthquake and tsunami: resilience and restoration. Tohoku J. Exp. Med., 226, 1-2.

Takahashi, K. \& Shibahara, S. (2020) A message for young authors: the past 100 years and future of the Tohoku Journal of Experimental Medicine. Tohoku J. Exp. Med., 250, 1-3. 